\title{
The Determinacy of Lexical Selectional Restriction and lts Basis for Existence *
}

\author{
Ma Qinghua ** \\ (Nanjing University, China) \\ Huang Yanqun ${ }^{* * *}$ \\ (Hangzhou Dianzi University, China)
}

\begin{abstract}
In this paper, the determinacy of regular lexical selectional restrictions is examined from both the internal structures of the single selectional restrictions (i.e. semantic selectional restrictions) and relationship between the structures of several selectional restrictions. Hence, our analysis and description are shifted from casual and indeterminate strings and markers on case basis to determined rules and circumspect dynamic systems, from lexical precepts to knowledge precepts, from the state of memory to rational deduction and rhetorical devices. Further studies indicate that selectional restrictions are intertwined structures, a feature that makes it possible to be one of the bases for lexical selectional restrictions to come into existence. Its related theories are the grarantee for scientific observations of selectional restriction structures.
\end{abstract}

Keywords: lexical selectional restriction, determinacy, intertwine, basis for existence

\section{Introduction}

Both syntax and lexicology study lexical relationship from different perspectives. Syntax focuses on the abstract syntactic relations between lexicons in syntagmatic structures, while lexicology on precepts of interlexical relations. Starting from lexical restriction relationship, a hot topic in both syntax and lexicology, this paper is to demonstrate the determinacy and ontological basis for regular lexical selectional restrictions (if we put aside pure paradigmatic relation and super selectional restriction relation) by the analytical studies on the relations between internal determinacy and external determinacy of semantic

\footnotetext{
* Project: National Social Sciences Founding Project (China), "Study of Sentence Complexity in Modern Chinese" (No. 11BYY084).

** Dr. Ma Qinghua: Professor, School of Liberal Arts, Nanjing University, Nanjing, 210046, China. E-mail: maqh86@ nju.edu.cn.

${ }^{* * *}$ Huang Yanqun, Hangzhou Dianzi University, Hangzhou, 310018, China. E-mail: teresahyq@ 163.com.
} 
selectional restriction structures, and to shift our analysis and description from casual and indeterminate strings and markers on case basis to determined rules and circumspect dynamic systems, from lexical precepts to knowledge precepts, from the state of memory to rational deduction and rhetorical devices. Furthermore, links for selectional restriction are intertwined structures, which is one of the bases for linking lexical selectional restrictions. Its related theories are the guarantee for scientific examination of selectional restriction structures in the Chinese corpus.

\section{The internal determinacy of selectional restriction structures}

The premise for scientific research into lexical relationship is to collect all data for studying lexical association in an objective, confirmative and easy way. In previous studies, whether in introspection or in survey, one word was chosen as the stimulus to retrieve its response words. It was not until their universality of psychological relations was estimated that the associative relations between them can be claimed. While the basic selectional restriction structure consists of a given word, a selectional restriction word and their relationship, the non-restrictive stimulus-response model that is conventionally adopted in the academic circle only takes the units into consideration, ignoring the relationship between units, as a result of which the data are considerably random and fall short of scientific description. Without semantic restriction, the number of response words is beyond measure which can be better shown in the stimulus-response model of noun, for example, zhēn (针, 'needle') as the trigger. To the contrary, the addition of the semantic relationship between the trigger and the unknown response word is conducive to the conclusion that response words can be the relatively target words. Compared with the non-restrictive stimulus-response model, this kind of restrictive stimulus model makes for objectivity and science with its substantially less random data.

\subsection{The concept of determinate selectional restriction structure}

Surely, the restrictive stimulus model is relatively limited in promoting the determinacy degree of word associations. Even if this model is adopted, the determinacy degree of word associations still varies from word to word, and from context to context. The concept of semantic selectional restrictions can be classified into the following types based on its scale:

a. a determinate concept as a word or a group of synonyms (Ma Qinghua, 2000:70) such as zuǐ/kǒu（嘴/口, 'mouth') in example 1;

b. the multiple closed or quasi-closed one, see example 2; 
c. semi-closed one, see example 3;

d. the open, see example 4.

The determinacy of selectional restriction structures depends on individual component in the selectional restriction set. The more potential selectional restriction concepts in the set, the more impossible it is to predict individual component. It is obvious that a-type selectional restriction concept is of highest determinacy while others of lower determinacy and higher indeterminacy. Members in b-type selectional restriction set cannot be activated as determinate as a-type but every concept is of high approachability and predictability. From type $b$ to type $c$, and to type $d$, the indeterminacy in selectional restriction concepts is characterized by their ascending order.

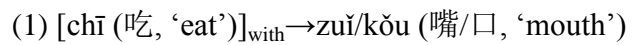

(2) [zhēn(针, 'needle') $]_{\text {damaged }} \rightarrow$ \{wān,duàn(弯,断,'bend,break')\}

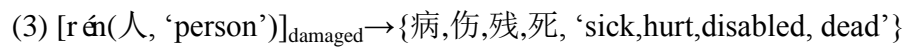

In the context of stimulus-response model and collective language knowledge, the selectional restriction concept inferred from the given word and its selectional restriction relationship is called the determinate selectional restriction concept. It can be classified into two types: the context-independent only in basic selectional restriction structures (including two units: the given word and selectional restriction concepts) (e.g.3), and the context-dependent in complex selectional restriction structures (including a given word and multiple selectional restriction concepts) and several selectional restriction structure chains (e.g. 4, 5). In the complex selectional restriction structures, sometimes an indeterminate selectional restriction concept (marked in italics) can make the following indeterminate selectional restriction concept (e.g. luò(落, 'drop') in 4a) of higher determinacy (e.g. dì(地, 'ground') in 4a) under the influence of elements like common sense. In an ongoing selectional restriction structure chain which results from combining routine knowledge and selectional restriction association (e.g $a \rightarrow b \rightarrow c \rightarrow d$ in 4 and $a \rightarrow b$ in 5), the selectional restriction concept, even if indeterminate in the subsequent structure, can be of higher determinacy and predictability for being a unit of the common sense chain (e.g. zāng(脏, 'dirty') in 4b, gānjìng (干净, 'clean') in 4d and yīfu (衣服, 'clothes') in 5b).

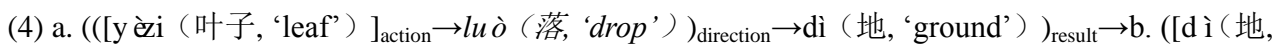

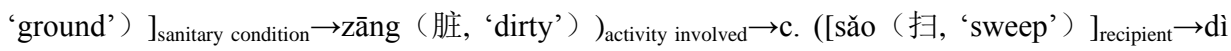

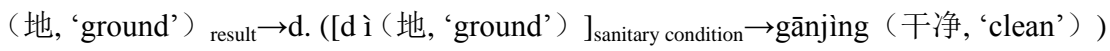

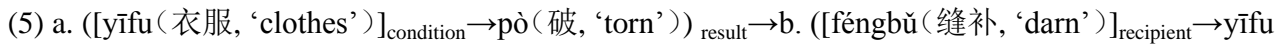
(衣服, 'clothes') ) 


\section{Ma Qinghua \& Huang Yanqun}

\subsection{Saturated selectional restriction concept}

Saturated selectional restriction is the concept that can form connotative combination with the given word. The determinate selectional restrictions concept in most basic selectional restriction structures (e.g.zuǐ/kǒu (嘴/口, 'mouth') in 1) belongs to the saturated selectional restriction concept while those in complex selectional restriction structures or structure chains (e.g. dì (地, 'ground') in 4a and yīfu (衣服, 'clothes') in 5b) are generally known as non-saturated selectional restriction concepts. In fact, the saturated selectional restriction concept is also a special form of deterministic selectional restriction concept Only by forming the connotative combination with a given word can saturated selectional restriction concept attain determinacy and if this condition is not taken into account, then it will even be of lower determinacy than some non-saturated selectional restriction concepts. For example, the selectional restriction concept in 8a triggers rén (人, 'person') more easily.

This concept seems to be tailored for the constraint of a given word, for constraint being the heterogeneous relationship or conceptual overlapping between lexical meanings (Ma Qinghua, 2005:2), the given word gives specific requirements for the characteristics of selectional restriction concept as if making a slot or blank and the sememe reflecting the requirement is represented by feminine sememe (marked by [o/]), for example, the feminine sememe for chī (吃, 'eat') being [O/+mouth]); the selectional restriction concept fills the slot or blank in compliance with the requirement and the sememe reflecting the filling requirement is represented by masculine sememe (marked by [ $\hat{o} /]$ ), for example, the masculine sememe for zuǐ (嘴, 'mouth') being [ $\hat{\delta} /+$ mouth]. The feminine sememe of a given word and the masculine sememe of saturated concept are identical with each other in content, just like replicas. ${ }^{\mathbb{1}}$

Three levels of saturated selectional restriction concept are specific saturated selectional restriction concept without the superordinate (e.g. 6a), general saturated selectional restriction concept about high-level abstract concept and the intermediate saturated selectional restriction concept, like 7a. Naturally, the formation of saturated selectional restriction concept is caused by semantics and structure. Semantically speaking, the specific saturated selectional restriction concept can describe things in a specific and expressive way (e.g. 6b); the intermediate one can intensify or disprove abnormal cases

\footnotetext{
${ }^{(1)}$ Empty sign(空符号) and full sign(满符号) are borrowed from Gordon Pask(戈登·帕斯克) and Susan Karan(苏珊. 卡冉)(1987). Xing Gongwan（1983:19） considers lexical collocation as complementary, but does not differentiate the correlated sememes, limiting the further study of the problem.
} 


\section{The Determinacy of Lexical Selectional Restriction and Its Basis for Existence}

(e.g. 7a); the general one can describe things in a generalized way.

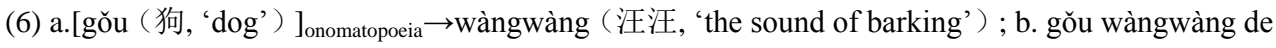
jiàozhe（狗汪汪地叫着, 'The dog is barking.')

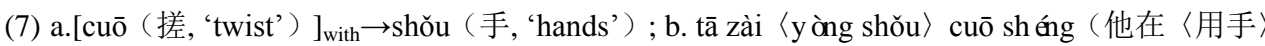
搓绳, 'He is making a rope by twisting strands together with his hands.') ; c. tā 〈shǒu〉 duàn le,zěnme cuō shéng (他〈手〉断了, 怎么搓绳, 'Since his 〈hands〉 are broken, how can he make a rope by twisting strands together?')

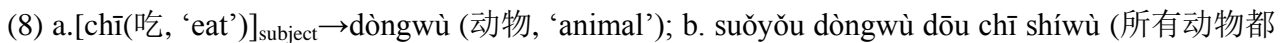
吃食物, 'All animals eat food.')

Structurally speaking, saturated selectional restriction concept can build several expressions into a chain of commons sense, for example, the verb-resultative construction (VRC) saturated selectional restriction concepts (e.g. 9a) are inverted routine knowledge linked by saturated predicate case (e.g. 9b) which enables the predicate to link multiple clustered case units. In saturated elements of the predicate case unit usually unidirectionally depends on the predicate (few bidirectional dependent relationship exists in the strict sense, as follows), showing that the unbalanced relationship may facilitate the predicate to "clasp" more case units.

(9) a.[liáocăo (潦草, ‘scrawled') ] preconditional verb $\rightarrow$ xiě (写, 'write'); b. ([liáocăo (潦草, 'scrawled') ] the

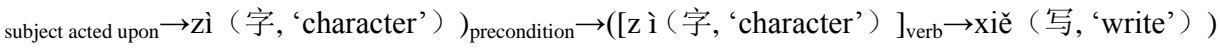

In the saturated structure composed of the given word and selectional restriction concept, there exists dependence between the saturated concept and the given word, which can be classified into unidirectional and bidirectional dependence.

\subsubsection{The unidirectional dependence of the saturated structure}

In the restrictive stimulus-response model, if a saturated selectional restriction concept $\mathrm{B}$ can be obtained from the given word A whereas a given word B cannot get a saturated selectional restriction concept $\mathrm{A}$, then the unbalanced relationship between $\mathrm{A}$ and $\mathrm{B}$ is called unidirectional dependence (Ma Qinghua, 2000:219). Comparing 10a and 10b:

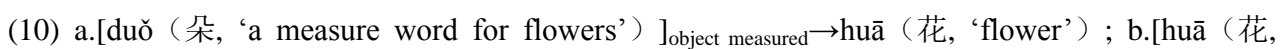

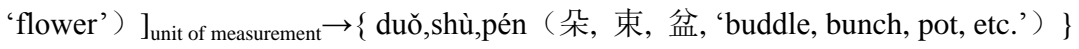

Of the saturated structure of unidirectional dependence, some saturated selectional restriction concept functions as the core of the syntactic meaning while others not. Those as the core, like the saturated selectional restriction verb in VRS (e.g. ex. I below) and the noun of saturated selectional restrictions in the noun-quantifier collocation (e.g. ex. II below), are quite small-scaled compared with the same type of non-saturated selectional 


\section{Ma Qinghua \& Huang Yanqun}

restriction structure. Wang Yannong \& Jiao Qun \& Pang Yong (1987) made a research into the collocation of verbs with 322 adjectives and verbs acting as resultative complements and with verbs. On the basis of the result, the conclusion after checking and calculating is drawn that there are only 2 cases of saturated structure (e.g. ex. I below) and that saturated structure with verb as the core of the saturated structure of selectional restriction concepts is 1/161 times the number of the non-saturated structure of its kind. Liu Xuemin \& Deng Chongmo (1989) examined over 8,000 nouns and 388 collocative quantifiers, of which we obtain 59 nouns that can be saturated selectional restriction concept and the other 329 nouns can only be non-saturated restriction concepts and the proportion between the saturated noun and the non-saturated is 1:5.6 through checking and calculating. Of the two structures, there's no chance for complementary predicate and quantifier to be selectional restriction concept.

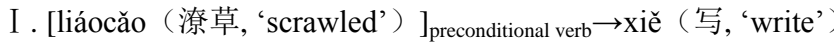

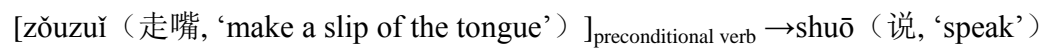

II . [fú （服, 'take') ] object measured $\rightarrow$ yào（药, 'medicine'）

[dǔ (堵, 'block') ] object measured $\rightarrow$ qiáng (墙, 'wall')

Here is the case unit in unidirectional dependent predicate relationship as no core of syntax, e.g. 11a. From a and b in e.g.11, we can see that 11a shows the unidirectional dependence.

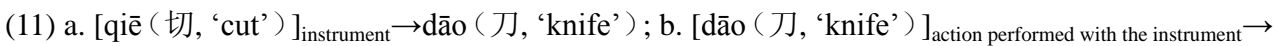
\{qiē,cì,kăn,duò,xuē（切, 刺, 砍, 剁, 削, 'cut,thorn,slash,chop,pare'） ...\}

The saturated selectional restriction concept of verbs can be the personal or animal subject ( e.g. ex. I below), the instrumental (the instruments, etc.), the by-s (parts of body) and the object (e.g. ex. II below).

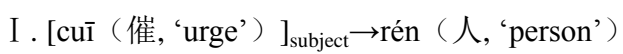

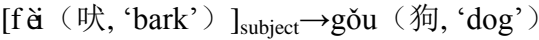

II . xiě (写, ‘write’ ) : \{rén（人, 'person'） subject, bǐ (笔, 'pen’) instrument $\} \mid$ duān (端, 'hold') : \{rén (人, 'person'） subject, shǒu（手, 'hands') with\}|kàn（看, 'look'）：\{dòngwù (动物, 'animal') subject, yăn (眼, ‘eyes') with) $\mid$ chī (吃, ‘eat') : \{dòngwù (动物, ‘animal') subject, zuǐ (嘴, 'mouth’) with, shíwù (食物, 'food') object

1.2.2 The bidirectional dependent saturated structure

In the restrictive stimulus-response model, if saturated selectional restriction concept B can be obtained from the given A and saturated selectional restriction concept A can also be obtained from the given $\mathrm{B}$, then the interdependence between $\mathrm{A}$ and $\mathrm{B}$ is called 
bidirectional dependence, equal to a circuit composed of two unidirectional dependence cases of different direction and type. Such can be shown in the saturated structure of onomatopoeia-noun and a few predicate-case relations, e.g. a and b in 12 and 13. Its units are saturated selectional restriction concepts to each other but the semantic types of constraint are different. B in 13 is at most quasi-saturated structure because instrument can act as something with fixed purpose or provisional function; for example, "the instrument" usually is used to "play" and to "beat or smack" as an attack provisionally.

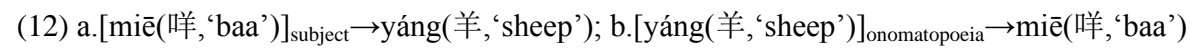

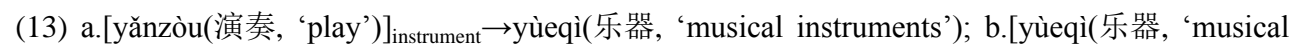

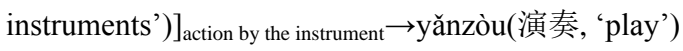

The bidirectional construct is much fewer than the unidirectional from the viewpoint of the total sum of numbers and internal scales and saturated structure fewer than the non-saturated in language. It is determined by the linguistic information theory principle that there is more chance for two random words to belong to a non-saturated structure than a saturated structure, because a saturated structure is a redundant and kind of "poorly used" structure except for emphasis. It is the fact that the saturated selectional restriction concept is the induction of the much larger amount of non-saturated selectional restriction concepts, e.g. the non-saturated structure Xiăomíng chī (小明吃, 'Xiaoming eats') | māma chī (妈 妈吃, 'mum eats') | gǒugou chī (狗狗吃, 'the dog eats') | xiăojī chī (小鸡吃, 'the chick eats'） etc. and the saturated structure dòngwù chī（动物吃, 'animals eat'）.

\subsection{Saturated selectional restriction meaning cluster}

When non-saturated selectional restriction concept is of such high indeterminacy that the set it is in becomes open, all concepts in the set have to be governed by a meaning cluster (i.e. the sememes formed by conjunction). Otherwise, the set is beyond control. Therefore, the psychologically indeterminate selectional restriction association becomes descriptively determinate but what is determinate concerns different object and way. The meaning cluster can be called "saturated selectional restriction meaning cluster", e.g. the open selectional restriction concept set in 14a and selectional restriction meaning cluster in 14b.

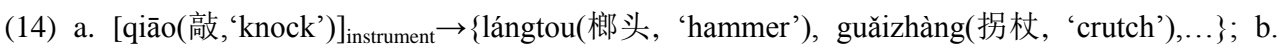
[qiāo(敲, 'knock') $]_{\text {object acted upon } \rightarrow[+ \text { object }+ \text { hard shell }]}$

Words referred to by the saturated selectional restriction meaning cluster form a lexical gap in the vocabulary system. The meaning cluster of lexical vacancy stems from induction from a certain number of non-saturated selectional restriction concepts or words (e.g. 14a) and its meaning is the same as that of a phrase (e.g. the meaning cluster in $14 \mathrm{~b}$ is the same 


\section{Ma Qinghua \& Huang Yanqun}

as phrase "object with hard shell".). It produces from the subconscious level, for example, a normal native speaker can generalize the mode of “qiāo(敲, 'knock')+[X]object” with qiāo(敲, 'knock') as the invariant from qiāo zhuōzi (敲桌子, 'knock the desk')|qiāo hēibăn (敲黑板, 'knoch the blackboard')|qiāo tāde tóu (敲他的头, 'knock his head')|qiāoqiāo qiáng(敲敲墙, 'knock the wall') etc. in different contexts based on the commonality seeking operation and subconsciously postulates that the conceptual value for $\mathrm{X}$ is "object with hard shell". However, there is no lexical item for X, so only the masculine meaning cluster [ $\delta /+$ object with hard shell] can directly govern all potential variants of $\mathrm{X}$, like non-saturated selectional restriction objects zhuōzi(桌子, 'desk') | hēibăn(黑板, 'blackboard') | tāde tóu(他的头, 'his head') | qiáng(墙, 'wall'), etc. and all potential variants can only be captured by the object of the masculine meaning cluster [\%/+object+hard shell]of chî(吃, 'eat') and the feminine meaning cluster is an ideology as a complex concept to reflect the recipient requirement and wait to be tenonned.

Meaning cluster is no fixed concept formed by words, inappropriate to act as the starting point of stimulus units or structural description in the restrictive stimulus-model. Thus structures including saturated selectional restriction meaning cluster can only be considered as unidirectional dependence, supporting the argument that unidirectional dependence has an advantage over bidirectional dependence.

\subsection{Candidate concept in multiple closed or semi-closed type}

If a given word is faced with a selectional restriction object of a multiple closed or semi-closed set in restrictive stimulus-response model, to choose and utilize every concept is indeterminate to some degree but it is not absolutely beyond prediction due to the closed-nature of the set. In the context selectional restriction association can be inferred from a specific word (e.g. 2 and 3) by the selectional restriction structure (including language inference and common sense, etc.) while it is different for an abstract word. The more abstract the given word, the more relevant synonyms (similar but different in constraint range), the more fuzzy the boundary of its connotative meaning, and as a result, the more difficult it is to carry out its deduction. Therefore, foreign students often make errors. Statistics about the prone-mistakes committed by both foreign and Chinese students in The Contemporary Chinese Mistakes and Correction Dictionary compiled by Yang Qinghui show that synonymy mistake account for $47 \%$ of the double sound word mistakes(Zhu Zhiping, 2004), most of which are abstract synonymies (e.g. 15 and 16) without regular connotation and boundary. Thus it is better to list the candidate concepts in selectional restriction set for plain explanation. For example, in Zhang Zhiyi(1981:65, 150) 
and Dictionary Compilation Bureau of the Language Research Institute of Chinese Academy of Social Sciences (2005), yōuliáng(优良, 'good') is used to modify personality, working style, skill, species, quality, tradition, condition and environment, while yōuxiù(优 秀, 'excellent') to modify people with high education and good quality, and man-made products, especially spiritual achievement, like staff, role or his knowledge, works, accomplishment and heritage; xuānbù(宣布, 'announce') can take nouns like fălìng(法 令, 'law'), jilü(纪律, ‘discipline’), zuìxíng(罪行,'crime’), míngdān(名单,'list'), jiéguǒ(结 果, 'result') as its objects, and some verbs and clauses like qìquán(弃权, 'abstain'), tuìchăng(退场, ‘exit'), chénglì(成立, ‘found'), jiēshòu yìjiàn(接受意见, ‘follow one’s advice'), guójiā dànshēng(国家诞生, 'a nationis founded'), mìnglìng(命令, 'command'), xīnwén(新闻, 'news') etc. can collocate with it, too.

(15) *tā shì yīgè 〈yōuliáng 〉de xuéshēng（他是一个〈优良〉的学生, 'He is a good student.')

(16) *nàgè dài yănjìng de lăoshī 〈fäbù 〉 le gèbān xuéshēng de míngdān (*那个戴眼镜的老师〈发 布〉了各班学生的名单, 'The teacher with glasses announces students' name list of all classes.')

\section{The determinate association between selectional restriction structures}

Several selectional restriction structures are linked up through such methods as language, common sense and rhetoric in an organic, even determinate way instead of in a disordered way. Therefore, based on his semantic experience, one can consciously expand his application by following a certain way and the determinacy doubtlessly is the cornerstone of this expansion. Xing Gongwan (1983:21) says, "It is difficult to understand the coexistence and collocation of each content word together with other content words in the same segment." However, another argument, "Lexical constraint can only be acquired by training in word and phrase collocation instead of inferring on a large scale like the morphological change" (Li Rulong and Yang Jichun, 2004) is questionable. If saturated structure and common sense are a large sum deposited in a bank, the potential entailment choice is like free withdrawal from its part deposit. Below are the three means of constituting deterministic links.

\subsection{Linguistic means}

Linguistic inference can be conducted by bridging the precepts of lexical paradigmatic association (mainly logic relation, like hyponymy) between the selectional restriction structures. The linguistic reference of selectional restriction structure means that selectional restriction structure B can be proved by inferring from the rightness of structure A on the 


\section{Ma Qinghua \& Huang Yanqun}

basis of linguistic association. The logic relations between lexical paradigmatic associations can be classified as hyponymy “niăo(鸟,'bird”) - máquè(麻雀,'sparrow’)”, polar opposites “zànchéng(赞成,'agree’) - fănduì(反对, ‘disagree’)”, relational opposites “jiāo( 教, ‘teach’) - xué(学, ‘learn’)”, synonymy “xìxiăo( 细小, ‘tiny’) - wēixiăo( 微 小, 'little')”, part - whole “niăo(鸟,'bird') - chìbăng(翅膀, ‘wing')” and synergy “lízi(梨 子,'pear') - píngguǒ(苹果, 'apple')”, etc (Ma Qinghua, 2006[1]:204) of which only hyponymy, complementary antonymy, relational opposite and synonymy act as bridging. Take hyponymy as an example:

(17) With saturated structure:[yănzòu (演奏, 'play') ] instrument $\rightarrow$ yuèqì (乐器, 'musical instruments'), and [yuèqì (乐器, 'musical instruments') ] hyponym $\rightarrow$ \{gāngqín, jíta, èrhú, dízi (钢琴, 吉他, 二 胡, 笛子,...'piano, guitar, erhu, flute, etc.') ], we have non-saturated construct: [yănzòu (演奏, 'play') ] instrument $\rightarrow\{$ gāngqín, jíta, èrhú, dízi（钢琴, 吉他, 二胡, 笛子..., ‘piano, guitar, erhu, flute, etc.' ) \}

In the course of inference, the selectional restriction concept is replaced by its hyponyms, most of which are nouns. There are three reasons for this: firstly, the number of nouns is far greater than that of predicates and other closed lexical items, which is universal in all languages; secondly, the sum of any noun's selectional restriction scale by collocation is enormously huge; lastly, the noun's application of common sense is more direct and large-scaled and the common sense could be directly drawn from abstraction and description of real objects instead of induction of precepts for lexical association in language (e.g. below). Therefore, nouns abound with hyponymy words which are available in collocation and replacement, like noun is replaced in 17 as a successful inference and verb is replaced in 18 as a failing inference.

(18) a. [yuèqì (乐器, 'musical instruments') ] ]action performed with the instrument $\rightarrow$ yănzòu (演奏, 'play') ; b. [yănzòu（演奏, 'play'） ] hyponym $\rightarrow\{$ chūi, lā, tán, chàng（吹, 拉, 弹, 唱, 'play, sing'） ...\}; c. [yuèqì (乐器, 'musical instrument') ] action performed $\rightarrow$ chuī (吹, 'play')

The inference of selectional restriction structure can be conducted by semantic and syntactic entailment in real expression. Semantic entailment means that the truth of A guarantees the truth of $\mathrm{B}$ while syntatic entailment means that the grammaticality of $\mathrm{A}$ guarantees that of B. Generally speaking, based on the replacement of hyponym by the superordinate nouns of selectional restrictions, the real expression of saturated structure can be considered as the semantic entailment for non-saturated structure (e.g.19) which can be considered as semantic entailment for another corresponding non-saturated structure (e.g. 20). Based on the replacement of superordinate by the hyponym nouns of selectional restrictions, the real expression of non-saturated structure can be considered as the 


\section{The Determinacy of Lexical Selectional Restriction and Its Basis for Existence}

syntactic entailment for saturated structure (e.g.21) and another corresponding non-saturated structure (e.g. 22). Interestingly enough, the semantic entailment is just the opposite to the syntactic entailment in order.

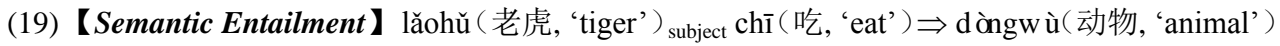
subject chī (吃, 'eat')

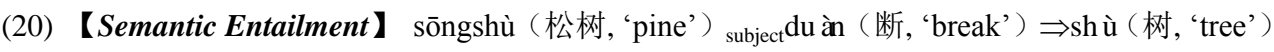
subject duàn (断, 'break')

(21)【Syntactic Entailment】dòngwù (动物, 'animal') ${ }_{\text {subject }} \operatorname{chī}$ (吃, 'eat') $\Rightarrow$ lăohŭ (老虎, 'tiger') subject chī (吃, 'eat')

(22)【Syntactic Entailment】 shù (树, 'tree'） subject duàn（断, 'break') $\Rightarrow$ sōngshù (松树, 'pine') subject duàn (断, 'break')

Semantic entailment may usually be damaged by negators but syntactic entailment cannot be cancelled in sentences.

(23)【Semantic Entailment】a. kàn zhǔrèn（看主任, 'look at the director') $\Rightarrow$ kànrén (看人, 'look at people') ; b. búkàn zhŭrèn（不看主任, 'don't look at the director'） ” búkàn rén（不看人, 'don't look at people')

(24)【Syntactic Entailment】 a. kànrén（看人, 'look at people') $\Rightarrow$ kàn zhǔrèn（看主任, 'look at the director') ; b. búkàn rén (不看人, 'don’t look at people’) $\Rightarrow$ búkàn zhǔrèn (不看主任, ‘don’t look at the director')

The balanced distribution of antonyms in some areas provide basis to linguistic inference. Balanced distribution is an important aspect of antonym (Ma Qinghua, 2000:151) though there exists unbalancedness in its usage (Zhan Renfeng \& Shi Anshi, 1986), which results from the nature of antonymy. The antonyms of balanced distribution can act as bridging in linguistic inference of selectional restriction structure. If $\mathrm{A}$ and $\mathrm{B}$ form a basic selectional restriction structure, antonym of $\mathrm{B}$, concept $\mathrm{C}$ can form selectional restriction structure with A in many cases, the combined meaning of the two selectional restriction structure is opposite to each other (〈năolì láodòng (〈脑力〉劳动, 'mental work') $\Rightarrow\langle$ tîlì láodòng ( $\langle$ 体力〉劳动, 'physical work') | shòudào〈xìnrèn〉 (受到〈信任〉, 'be trusted') $\Rightarrow$ shòudào 〈huáiyí 〉 (受到 〈怀疑〉, 'be suspected') ). The unbalanced antonymy shows that inference on the basis of high probability can only yield higher determinacy by increasing limitation.

\subsection{Application of common sense}

The analysis of lexical collocation involves common sense; illustrating meaning and syntax also shows its systematic insufficiency when it comes to be involved with common sense. (Ma Qinghua, 2005:414-416) Common sense refers to the routine semantic 


\section{Ma Qinghua \& Huang Yanqun}

knowledge in the knowledge system and there exists unidirectional dependence on common sense of selectional restriction structure, at least concerning two relational models.

\subsubsection{Natural linkage selectional restriction by procedural knowledge}

The daily procedural knowledge is a kind of common sense for linage of several declarative relationships (Ma Qinghua,2000:250). The saturated structures or non-saturated structures involved with predicate can be naturally lined up on the basis of procedural knowledge and all these selectional restriction structures correspond to an event. (e.g. 9b and 4-5)

\subsubsection{Inference with common sense as the insignificant premise}

Sometimes a new selectional restriction structure can be inferred by means of certain common sense, this kind of inference between the extralinguistic world and linguistic system is called "common sense and language inference".

Meaning cluster can expand the scale for the determinate association between selectional restriction structures. Meaning cluster is no fixed concept expressed by words, and in a restrictive stimulus-response model, it is unsuitable to be a stimulus unit or the starting point of structural description. However, it can act as transition in or insignificant premise for the inference between selectional restriction constructs by using common sense concerning relevant nouns instead of linguistic knowledge. Of all parts of speech, the application of common sense by nouns is the most direct and abundant and the common sense is about the abstraction and description of reality characteristics instead of induction of precepts of lexical association in language. The selectional restriction concepts of nouns are of various kinds. The definition of a noun includes some common sense component, which corresponds to a statement with regard to meaning(Ma Qinghua, 2000:255), and it contains all basic original information of lexical collocation and the original selectional restriction structures, available as the starting point of semantic inference. The definition of the noun zhēn (针, 'neddle') in Contemporary Chinese Dictionary is like 25a. We can capture its concept directly from reality without relying on the linguistic induction. The aforementioned common sense concerning zhēn (针, 'neddle') can be decomposed into common sense components, as described in $25 \mathrm{~b}$, in which some original selectional restriction structures are connotated (e.g. 25c).

(25) a. zhēn shì xìcháng ${ }_{[1]}$, zhēnzhí $_{[2]}$, tiáoxíng ${ }_{[3]}$, yìngzhì ${ }_{[4]}$, xiăo ${ }_{[5]}$, wùtǐ ${ }_{[6]}$, yìtóu jiān ${ }_{[7]}$, shì féngbǔ yīfu de gōngjù ${ }_{[8]}$, lìng yītóu yǒukǒng ${ }_{[9]}$, yònglái yǐnxiàn ${ }_{[10]}$ (针是细长 ${ }_{[1]}$ 、直 ${ }_{[2]}$ 条形 ${ }_{[3]}$ 、硬质 $[4]$ 、 小 $_{[5]}$ 物体 $_{[6]}$, 一头尖 ${ }_{[7]}$, 是缝补衣物的工具 ${ }_{[8]}$, 另一头有孔 ${ }_{[9]}$, 用来引线 ${ }_{[10]}$, the needle is tiny 


\section{The Determinacy of Lexical Selectional Restriction and Its Basis for Existence}

and tapering $\left[{ }_{[1]}\right.$, straight $_{[2]}$, bar-shaped ${ }_{[3]}, \operatorname{hard}_{[4]}$, tiny ${ }_{[5]}$, object ${ }_{[6]}$, sharp at one end ${ }_{[7]}$, tool for sewing $_{[8]}$, a pinhole at the other $\operatorname{end}_{[9]}$, for threading ${ }_{[10]}$ ' $)$

b. zhēn(针, 'neddle'): \{(针细长); (针直); (针条形); (针是硬质的); (针小); (针是物体); (针一 头尖); (针是缝补衣物的工具); (针的另一头有孔); (针用来引线) $\}$

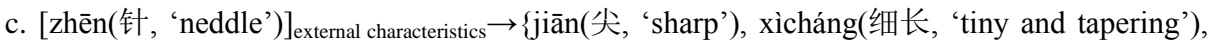

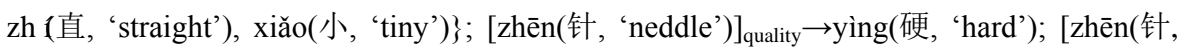

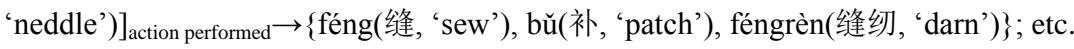

New selectional restriction structures can be inferred from some original structures based on linguistic inference, e.g. the antonymy inference in 26.

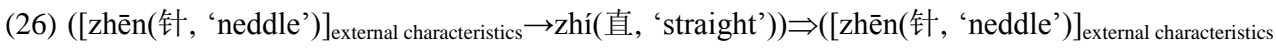

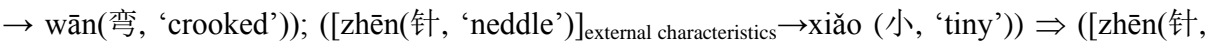

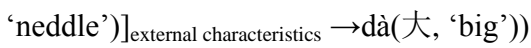

A new selectional restriction structure can be inferred from some selectional restriction structures of predicate relation by means of common sense concerning the noun. In example 27, the feminine meaning cluster of duàn (断, 'break') is prepared for choosing appropriate object, involved in the linguistic category, while the masculine meaning cluster of shéngzi (绳子, 'rope') is from human experience in the real environment and represents the meaning of the noun shéngzi (绳子, 'rope'), involved in the common sense and linguistic category, but more in the common sense category because an object $\mathrm{X}$ with the long bar-shaped characteristics can be theoretically included in non-saturated structure “[duàn (断, 'break') ] subject $\rightarrow X$ " provisionally though failing to give its specific name.

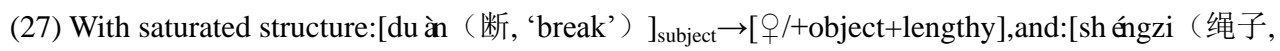

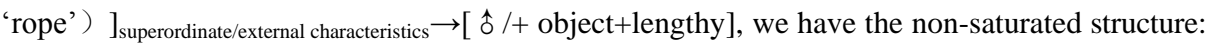

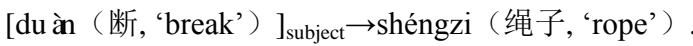

\subsection{Rhetorical devices}

The rhetorical devices used in conventional selectional restriction collocation are conventionally limited and cannot be deviant, that is, excluding deviant collocation. Synecdoche and metonymy are conventional rhetorical devices in lexical usage, expanding the range of lexical selectional restriction linkage and building a bridge of meaning equivalence between the two selectional restriction structures before or after the rhetorical devices used.

Synecdoche means that part stands for the whole, the whole for part, the genera for the species or the species for the genera. The semantic inference through synecdoche between selectional restriction structures is conducted only in two ways: 1. part stands for the whole 


\section{Ma Qinghua \& Huang Yanqun}

(e.g. 28 and 29); 2. advance towards the superordinate concept of the original concept, that is, the category for the specific type ( e.g. 30 and 31). Thus, if the original concept is saturated selectional restriction concept, synecdoche makes the new selectional restriction structure ambiguous oversaturated structure. And the semantic determinate association may be lost by inverting the starting point, e.g. 31a cannot be inferred by $31 \mathrm{~b}$ in 31 .

(28) a. ([dădòng（打动, 'touch') ] recipient $\rightarrow$ rénxīn（人心, 'people's heart') ) synecdoche $\rightarrow$ b. ([dădòng

(打动, 'touch') $]_{\text {recipient }} \rightarrow$ rén (人, 'people') )

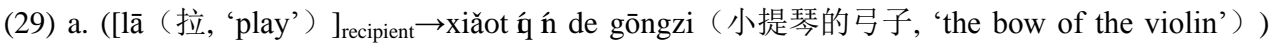

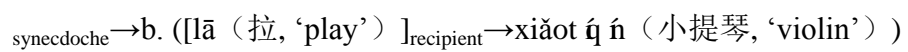

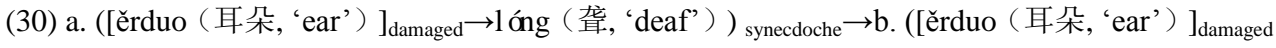
$\rightarrow$ cánfèi (残废, 'disabled') )

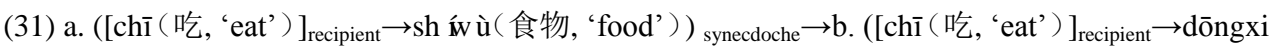
(东西, 'something') )

Metonymy is formed based on association, for example, contiguity, coexistence and cause-effect relation with such common types as the method standing for the subject, cause for the effect, material for the product and process for the product. Take the selectional restriction structure of metonymy as example: $32 \mathrm{~b}$ is realized by adopting the metonymy of the product for the process.

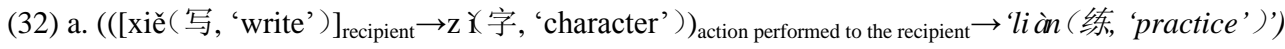
mytonymy $\rightarrow$ b. ([zì (字, 'character') ] ]action performed to the recipient $\rightarrow$ liàn (练, 'practice') )

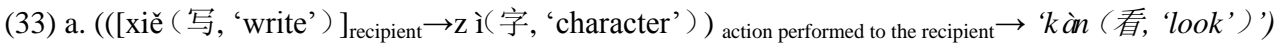
mytonymy $\rightarrow$ b. ([zì (字, 'character') ] ]action performed to the recipient $\rightarrow$ kàn（看, 'look'）)

At best the general rules of formation for the links of selectional restricted structures formed by rhetorical devices can be generalized but in nature the structure belongs to the linguistic agreement category with little deduction, for example, in $31 \mathrm{~b}$ the result $\operatorname{ch} \overline{1}($ 吃,

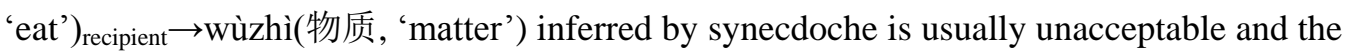
latter not conventional selectional restriction association except for fun, speaking in a humorous way. $33 \mathrm{~b}$ cannot be inferred from 33a through synecdoche.

\section{The intertwined selectional restriction structure}

A little more thought about the aforementioned analysis enables us to come to the conclusion that selectional restriction structure and theories about it can only be intertwine hierarchical structures, as the foundation for the existence of selectional restriction structure and its theoretical guarantee for scientific examination of selectional restriction 
structure. Strange loops emerge in the system of intertwine hierarchical structure as we go through certain level upward or downward the hierarchical system and find ourselves in the same place where we start our journey. All levels intertwine with and permeate, which imply infinite concepts (D. R. Hofstadter, 2001:15, 20). Zhou Guoguang (2002) and Qian Guanlian (2002) introduced Kurt Godel's multilayer intertwine or strange loops theory into his examination of lexical problems directly or indirectly, but both are restricted to the explanations of the following linguistic common sense theories: the meaning of any word cannot explain itself and can only be explained by other words; other words cannot explain themselves either and can only be explained by other different words and the rest could be deduced from this. Actually, many intertwine structures hidden in the lexical selectional restriction association and its theories justify its existence and normal operation.

3.1 Intertwinement between the internal elements of selectional restriction structures

The internal elements of selectional restriction structures include the given word, selectional restriction elements and selectional restriction relation. The meaning intertwine and permeate between the given word and selectional restriction elements shows itself in the intermeshing between the feminine sememe of a given word and masculine sememe of the selectional restriction concept and between the feminine meaning cluster of a given word and masculine meaning cluster in the open selectional restriction set (mentioned before). The meaning intertwine between selectional restriction relation and selectional restriction units shows itself between the given word and the selectional restriction concept. It climbs upward the abstract steps and finally becomes a duplicate of the selectional restriction relation. (e.g. compare a and b in 34 and 35 below.)

\subsection{Syntagmatic and paradigmatic intertwinement}

The selectional restriction linkage at syntagmatic level cannot be thoroughly described without considering the lexical relation at the paradigmatic level. There are two reasons for this: firstly, the determinate relation between selectional restriction structures can only be established by means of certain relations on paradigmatic level. Secondly, the hierarchy of the conceptual classification at paradigmatic level is different from the abstract level required by selectional restrictions at syntagmatic level, but the two are closely related. The concept classification system on paradigmatic level usually has 5 or 6 levels, which are named according to scientific nomenclature from the abstract to the specific: most abstract name like zìrán (自然, 'nature'), abstract name like dìmào (地貌, 'landscape'), less abstract name like shān(山, 'mountain'), specific name like huǒshān(火山, 'volcano'), more 


\section{Ma Qinghua \& Huang Yanqun}

specific name like huó huǒshān(活火山, 'active volcano'), and most specific name like āsūshān(阿苏山, 'Asosan')(Ma Qinghua, 2000:26). Selectional restriction requirements on syntagmatic level do not correspond accurately to the hierarchical system but can be classified into different levels of abstraction with the saturated selectional restriction concept into specific, intermediate and general selectional restriction concept corresponding to the low, intermediate and high level with regard to abstraction. Li Rulong \& Yang Jichun (2004) divided lexical selectional restriction linkage into semantic constraint and semantic collocation and they pointed out that: "Lexical constraint stems from semantic constraint and the restrictions of lexical collocation which seems to go beyond motivation, but to be governed by linguistic conventions." Indeed they classified lexical selectional restriction linkage into two levels, the semantic collocation relation with the selectional restriction linkage of specific word, and the semantic restrictive relation with the selectional restriction linkage of generic word or mid-lever word (a word that is somewhere between the specific word and generic word). Obviously, there is no point decomposing the selectional restriction requirements on syntagmatic levels into abstract levels if there is no conceptual classification hierarchy on paradigmatic level.

3.3 The multi-intertwinement of selectional restriction hierarchies among three levels of psychology, expression and description

Selectional restriction structure can be divided into psychological, expressive and descriptive levels: the restrictive stimulus-response model belongs to the psychological level (e.g. 34a), collocation in natural language flow the expressive level (e.g. 35a), and semantic component analysis the descriptive level or metalanguage level (e.g. 36a). The distinction among the three levels gives us a clear picture of the multi-tangled hierarchies of selectional restriction structure. The three selectional restriction structures at the psychological, expressive and descriptive levels correspond to and reflect each other, as if they were building a house. The selectional restriction elements go through continuous changes during its course of the three levels but their correspondent relations on the three levels seem quite clear: in the psychological level, some originate from concepts through the memory channel, some usages about the scale of selectional restriction objects through the linguistic consciousness; on expressive level, some come from words and concepts and some from lexical gap, like the saturated selectional restriction concept of qiāo (敲, 'knock') ; at the descriptive level, some stem from sememes and meaning clusters. Their corresponding relations are shown in the following table:

Table 1. Level of Selectional Restriction Structures and Category of Selectional Restriction Elements 
The Determinacy of Lexical Selectional Restriction and Its Basis for Existence

\begin{tabular}{|c|c|c||}
\hline Level of Selectional Restriction Structures & \multicolumn{2}{|c|}{ Category of Selectional Restriction Elements } \\
\hline Psychological Level & concepts in the memory & linguistic consciousness about usage \\
\hline Expressive Level & word & lexical gap or substitute phrase \\
\hline Descriptive Level & sememe & meaning cluster \\
\hline
\end{tabular}

However, the seemingly explicit hierarchical structure cannot be justified by the following aspects, turning to a strange loop.

Firstly, categories available for mastering the saturated selectional restriction elements can only be concepts or words on psychological and expressive levels and the meaning cluster on descriptive level. In the beginning it is repetitive work to list another equivalent sememe when a concept exists, for the latter takes an advantage over word in that a word cannot cover all synonymous variant under the same concept (e.g. the word gāoxìng (高兴, happiness) does not cover the meaning of xǐyuè (喜悦, 'joy'), yúkuài (愉快, 'elation'), huānlè (欢乐, 'rapture') etc.) while word takes an advantage over concept in its real existence in language. Besides, in such cases there is no available concept and only substitute phrase in expression, meaning cluster can glue the meaning to be expressed with its ability to capture and glue the unintentionally-expressed and non-emerging content for comparison and reflection. Therefore, it is best to start from the concept and word on psychological and expressive level and the meaning cluster on descriptive level but they cannot concur in any set of the three selectional restriction structures, which leads to the level-crossing of the three but they are complementary.

Secondly, when the same selectional restriction structure is located at the three different levels of psychology, expression and description, the existing or implicit structural linkage, namely selectional restriction relation between the given word and the selectional restriction elements is invariant (e.g. the three levels in 34-36 are all "process-instrument" relation). However, the strange loop linked up among the three levels according to abstract degree gets this invariant selectional restriction linkage involved. On psychological and expressive level, the given word and selectional restriction word / concept can finally become the replicate of the contents of selectional restriction relations if they keep on climbing the abstract ladder simultaneously (see a and b in 34 and 35). Meanwhile, on descriptive level, they are also the replicate of certain core sememes of the original given word and the original selectional restriction word/concept (hyponymically related to the rational meaning, like the core sememe for hóuzi（猴子, 'monkey') being [+animal](Ma Qinghua, 2000:182). See the selectional restriction unit and linkage in $34 \mathrm{~b}$ and $35 \mathrm{~b}$ and the core sememe in 36 . 
(34)【Psychological Level】 a.[duò(槑, ‘chop')] $]_{\text {instrument for action performing } \rightarrow \text { dāo(刀, 'knife'); b. [xíngwéi }}$ (行为, 'action')]

(35)【Expressive Level】a. yòng dāo duò (用刀槑, 'chop with a knife') action-instrument; b. yòng gōngjù xíngdòng (用工具行动, 'to act with a tool') action-instrument

(36)【Descriptive Level】 a. duò(槑, ‘chop'): [+action,...]; b. dāo(刀, 'knife'): [+instrument,...]

Descriptive level provides explanation for the expressive level and description can only be carried out with the abstraction of the higher level so the descriptive level tries its best to be more abstract. For this reason, mostly the superordinate of a word must be a sememe on its descriptive level and the descriptive level mainly takes saturated structure as described object. In the expressive level, it is conducted for the most part in the lowest position of the ladder of the abstraction due to the rarer presence of saturated structure (usually considered information redundant and bad structure) and over-saturated structure (formed for ambiguous expression) than the non-saturated structure. A given word can also present itself at the expressive level of the saturated selectional restriction structure with the same identity, as in 37a but cannot at the descriptive level of its selectional restriction structure except for its substitution by its superordinate as in $37 \mathrm{~b}$.

(37) a. rén yòng huòbì cóng tārén nà'er $<$ măi > wùpǐn（人用货币从他人那儿<买>物品, "people use money to < buy> goods from others.') ; b. "măi (买, 'buy') ": rén yòng huòbì cóng tārén nà'er $<$ huànqǔ > wùpǐn (人用货币从他人那儿<换取>物品, 'people use money to <exchange > goods from others.')

3.4 The meaning intertwinement of selectional restriction hierarchy in the sublevels under the three levels

The sublevels under the same level show the intertwine relation between each other, for example, the intertwinement between the metalanguage and the object language at the descriptive level and between the syntax and lexical collocation at expressive level.

3.4.1 The intertwine between the metalanguage and the object language on the descriptive level

The intertwine between the metalanguage and the object language on the descriptive level widely spreads in the relation between language and its definition, which has been a common sense of linguistics.(Ma Qinghua, 2000:26) In 38a the object language is included in the metalanguage which form an intertwined nonsense structure.(Ma Qinghua, 2006: 372-373) However, if we make slight changes or make some efforts, by means of synonymous substitution of găndòng (感动, 'move') for dădòng (打动, 'touch') ${ }^{\mathbb{1}}$ though

\footnotetext{
(1) Wu Weitian (1999:87) describes the 'relational sememe' (we called 'feminine sememe') of dădòng (打 动, 'touch') as 'kě shòu găndòng de'(可受感动的, 'touchable'), transcribed as in 38b.
} 
substitution of synonym causes increasingly greater errors, the descriptive methods can be accepted, the reason for which may be that it acquires its own value and meaning during the equivalent substitution. "Structure by synonym substitution gains meaning", (D. R. Hofstadter, 2001:66-67) which means that describing the same thing in different ways generates a number of expressions which can gain acceptable meaning by synonymous substitution.

(38) a.dădòng (打动, 'touch') : [ $Q /+$ touchable]; b. dădòng (打动, 'move' ) : [ + /+movable]

\subsubsection{The intertwinement at the level of syntax and lexical collocation}

The nonsense caused by internal intertwinement at the same level can be removed through resort to the intertwinement between the level of syntax and lexical collocation. For example, the intertwined structure between metalanguage and object language presents itself in the lexical intertwinement between different syntactical levels at the expressive level, as in 39, the real expression of 38.

(39) ? dădòng kě bèi dădòng de (' 打动可被打动的, 'touch what can be touched')

Besides, the nonsense can be removed through resort to substituting word of the same surface meaning for part of the phrase, as follows:

? chī kěchī de dōngxi（'吃可吃的东西, 'eat what can be eaten') $\rightarrow$ chī shíwù (吃食物, 'eat food')

l'hē kěyǐ hē de yǐnliào（'喝可以喝的饮料, 'drink what can be drunk') $\rightarrow$ hē yǐnliào（喝饮料, 'drink

drinks') |'dú kě dú de dōngxi ('读可读的东西, 'read what can be read') $\rightarrow$ dú dúwù (读读物, 'read reading materials')

The conceptualization process conforms to the reality process: some new items prove to be eatable before they are categorized as shíwù (食物, 'food') . Interestingly enough, after the process the redundant structure of saturated constraint finds that the connotation of some selectional restriction words is wider than that of the correspondent phrase prior to conceptualization (for example, the syntactic entailment "chī niúnăi ("吃牛奶, 'eat milk') cannot be inferred from chī shíwù (吃食物, 'eat food') ) and narrower than that of the correspondent phrase prior to conceptualization (for example, the semantic entailment he y̌nliào（喝饮料, drink drinks） cannot be inferred from hējiǔ (喝酒, 'drink wine') ).

The above analysis indicates that intertwinement feature is an important basis on which lexical selectional restriction linkage exist and function and also a significant part of the lexical selectional restriction theory. As some scholars say, the strange loop of hierarchical intertwine is no longer of negative value and is of positive value or harmony at higher level.

(D. R. Hofstadter, 2001) 


\section{Ma Qinghua \& Huang Yanqun}

\section{Conclusion}

This paper gives a description and analysis of the internal determinacy of selectional restriction structure, the determinate linkage between the selectional restriction structure and the intertwinement features of selectional restriction structure. It is necessary for second-language vocabulary teachers to attach great importance to the internal determinacy of lexical selectional restriction structure and determinate relation between selectional restriction structures. Since intertwinement feature is the basis of selectional restriction linkage, intertwinement theory enables the scientific analysis of selectional restriction structure and the whole lexical system and guarantees their application to practice. In additions, the process of argumentation for the intertwinement feature of selectional restriction structure enables us to recognize the intertwinement nature of the whole linguistic system.

\section{References}

Anderson, J. R. 1989[1980]. Cognitive Psychology and Its Implications (认知心理学) [M]. Tr. by Yang Qing, Zhang Shuzu, et al.. Changchun: Jilin Education Press.

Dictionary Compilation Bureau of the Language Research Institute of Chinese Academy of Social Sciences. 2005. Contemporary Chinese Dictionary [M]. Beijing: Commercial Press.

Hofstadter. D. R. 2001[1979]. Gödel, Escher, Bach: An Eternal Golden Braid (哥德尔、艾舍尔、巴赫— 集异璧之大成) [M]. Tr. by Guo Weide, et al.. Beijing: Commercial Press.

Li Rulong \& Yang Jichun. 2004. Vocabulary Teaching is the Center in Teaching Chinese as a Second Language [J]. Journal of College of Chinese Language and Culture of Jinan University, (4):21-29.

Liu Xuemin \& Deng Chongmo. 1989. A Dictionary of Modern Chinese Classifier-noun Collocation [C] .Hangzhou: Zhejiang Education Press.

Ma Qinghua. 2000. Cultural Semantics [M]. Nanchang: Jiangxi People's Press.

Ma Qinghua. 2005. On Self-organization of Coordinate Structure [M]. Shanghai: Fudan University Press.

Ma Qinghua. 2006. The Multidimensional Research of Semantics [M]. Beijing: Language and Literature Press. 372-373.

Pask, G. \& S. Curran. 1987[1982]. Micro man: Computers and the evolution of consciousness (电脑、信息 与人类) [M]. Tr. by Wu Yihua, Shen Zuliang, Beijing: Chinese Prospect Press.

Qian Guanlian. 2002. On the Theory of Language Holograph [J]. Foreign Language Research, (2):20-26.

Wang Yannong \& Jiao Qun \& Pang Yong. 1987. A Dictionary of Chinese Verb-Res [M]. Beijing: Beijing Language Institute Press.

Wu Weitian. 1999. Chinese Computational Semantics [M]. Electronic Industry Press.

Xing Gongwan. 1983. Collection of Chinese Language Theses [M]. Beijing: Commercial Press.

Zhan Renfeng, Shi Anshi. 1986. The Commonality, Category and Unbalancedness of Antonym Paradigm [A]. Yang Shengchu, Li Bochao: Collection of Theses on Chinese Semantics [C]. Changsha: Hunan People's Press. 2:395-411.

Zhang Zhiyi. 1981. Concise Chinese Dictionary of Synonyms [M]. Shanghai: Shanghai Dictionary Press.

Zhou Guoguang. 2002. The Winding of Meaning and the Inevitability of the System of Vocabulary [J]. The Journal of Nanjing Normal University, (3): 108-114.

Zhu Zhiping. 2004. Error Analysis on Chinese Dissyllabic Compounds in Semantics [J]. Chinese Research, (2): 61-65. 